\title{
Synthesis of the C4-Epi-Lomaiviticin B Core Reveals Subtle Stereoelectronic Effects
}

\section{Citation}

Lee, Amy S., and Matthew D. Shair. 2013. "Synthesis of the C4-Epi-Lomaiviticin B Core Reveals Subtle Stereoelectronic Effects." Organic Letters 15 (10) (May 17): 2390-2393. doi:10.1021/ ol400832r.

\section{Published Version}

doi:10.1021/ol400832r

\section{Permanent link}

http://nrs.harvard.edu/urn-3:HUL.InstRepos:34268564

\section{Terms of Use}

This article was downloaded from Harvard University's DASH repository, and is made available under the terms and conditions applicable to Other Posted Material, as set forth at http:// nrs.harvard.edu/urn-3:HUL.InstRepos:dash.current.terms-of-use\#LAA

\section{Share Your Story}

The Harvard community has made this article openly available.

Please share how this access benefits you. Submit a story.

\section{Accessibility}




\section{Synthesis of the C4-Epi-Lomaiviticin B Core Reveals Subtle Stereoelectronic Effects}

XXXX

Vol. XX, No. XX 000-000
(1) (a) He, H.; Ding, W. D.; Bernan, V. S.; Richardson, A. D.; Ireland, C. M.; Greenstein, M.; Ellestad, G. A.; Carter, G. T. J. Am. Chem. Soc. 2001, 123, 5362-5363. (b) Woo, C. M.; Beizer, N. E.; Janso, J. E.; Herzon, S. B. J. Am. Chem. Soc. 2012, 134, 15285-15288.

(2) $\beta$-Alkoxyenone may undergo an elimination-aromatization pathway.

(3) (a) Nicolaou, K. C.; Denton, R. M.; Lenzen, A.; Edmonds, D. J.; Li, A.; Milburn, R. R.; Harrison, S. T. Angew. Chem., Int. Ed. 2006, 45, 2076-2081. (b) Nicolaou, K. C.; Nold, A. L.; Li, H. Angew. Chem., Int. Ed. 2009, 48, 5860-5863. (c) Zhang, W.; Baranczak, A.; Sulikowski, G. A. Org. Lett. 2008, 10, 1939-194. (d) Feldman, K. S.; Selfridge, B. R. Org. Lett. 2012, 14, 5484-5487.

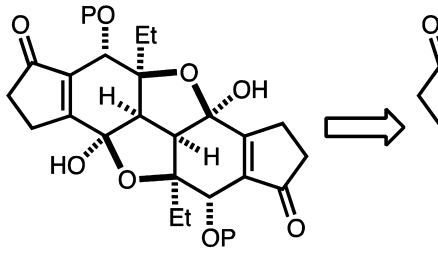

Lomaiviticin B Core
The lomaiviticins comprise a family of type-II polyketide natural products with remarkable $C_{2}$-symmetric structures Micromonospora lomaivitiensis, and exhibit an array of biological activity. ${ }^{1}$ Lomaiviticin A (1) is potently cytotoxic (2) are antibiotics against Gram-positive bacteria.

synthetic challenges. The highly oxidized carbon skeleton includes up to four 2-deoxyglycosides, and the central $\mathrm{C} 2-\mathrm{C}_{2}^{\prime}$ bond links two densely functionalized halves to naphthazarin, and a $\beta$-alkoxyenone subunit. ${ }^{2}$ Altogether, these features render the lomaiviticins challenging targets.

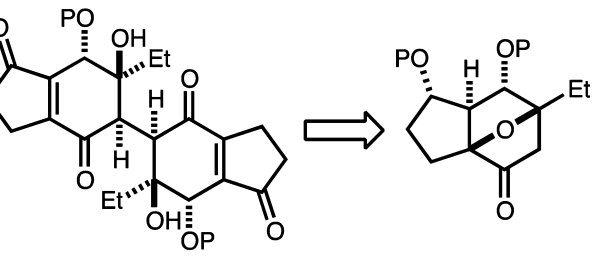

Lomaiviticin A Core

An efficient synthesis of the C4-epi lomaiviticin B core is reported. The synthesis features a diastereoselective anionic formal furan Diels-Alder reaction and a stereoselective oxidative enolate dimerization. During the investigation, subtle yet critical stereoelectronic effects imparted by the

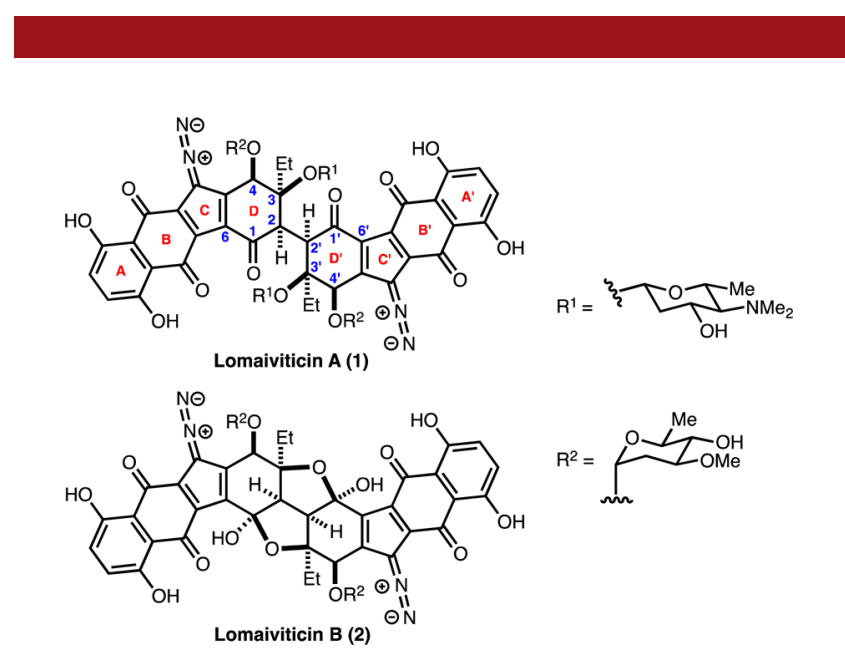

Figure 1. Structures of lomaiviticin A (1) and B (2).

Indeed, despite efforts by various groups, ${ }^{3,4}$ only one synthesis of the aglycon $(3$, Scheme 1$)$ has been accomplished to date. ${ }^{5}$

Our retrosynthetic analysis of the lomaiviticin aglycon (3) is outlined in Scheme 1. We envisioned that the

(4) (a) Krygowski, E. S.; Murphy-Benenato, K.; Shair, M. D. Angew. Chem., Int. Ed. 2008, 47, 1680-1684. (b) Lee, H. G.; Ahn, J. Y.; Lee, A. S.; Shair, M. D. Chem.-Eur. J. 2010, 16, 13058-13062. 
Scheme 1. Retrosynthetic Analysis of Lomaiviticin Aglycon (3)

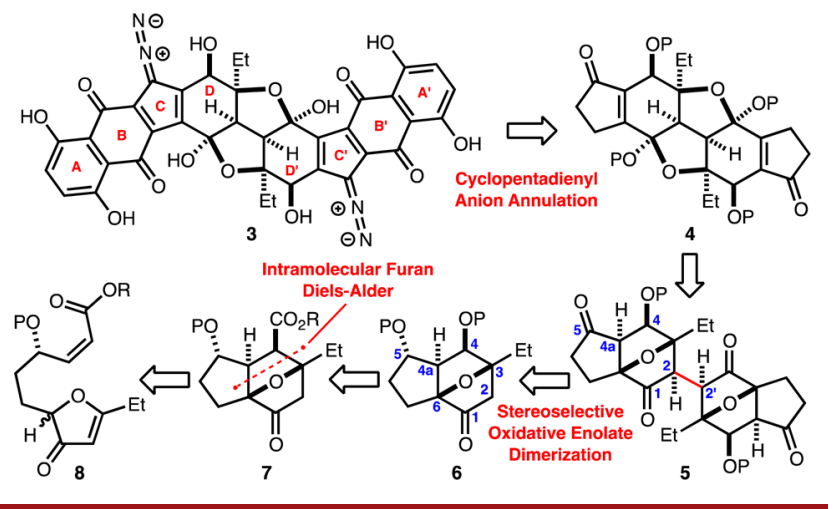

$\mathrm{AB} / \mathrm{A}^{\prime} \mathrm{B}^{\prime}$-naphthalenes of $\mathbf{3}$ could be constructed from lomaiviciting $\mathrm{B}$ core $\mathbf{4}$ via a late-stage cyclopentadienyl anion bisannulation. ${ }^{6} 4$ could arise from oxanorbornanone dimer 5, where the key $\mathrm{C} 2-\mathrm{C} 2^{\prime}$ bond would be established through a stereoselective oxidative enolate dimerization of monomer $\mathbf{6}$. The oxanorbornanone system could be constructed from an intramolecular exo-selective furan Diels-Alder reaction of a suitable precursor.
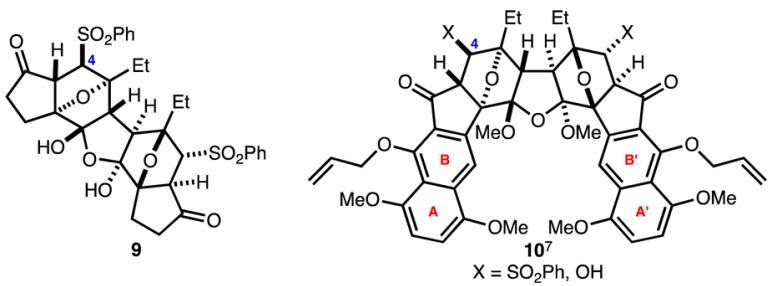

Figure 2. Previous work from the Shair group. ${ }^{7,8}$

Arguably, the stereoselective construction of the key $\mathrm{C} 2-\mathrm{C} 2^{\prime}$ bond presents the most formidable obstacle in designing a route toward the lomaiviticins. Constructing the $\mathrm{C} 2-\mathrm{C} 2{ }^{\prime}$ bond via a dimerization strategy is complicated by two critical challenges: (1) a high potential for $\beta$-elimination of the $\mathrm{C} 3$-alkoxy group from a $\mathrm{C} 1-\mathrm{C} 2$ enolate and (2) difficulty in achieving stereoselective formation of the $\mathrm{C} 2 / \mathrm{C} 2^{\prime}$ stereocenters. To address this, our lab has developed a strategy utilizing the oxidative enolate dimerization of an oxanorbornanone system. ${ }^{4}$ Stereoselective formation of the $\mathrm{C} 2$-stereocenter is controlled by dimerization of the enolate from the less hindered convex exo face of the oxanorbornanone. In the oxanorbornanone system, $\beta$-elimination is prevented due to the nearly orthogonal orientation of the endocyclic enolate $(\mathrm{C} 1-\mathrm{C} 2)$

(5) (a) Herzon, S. B.; Lu, L.; Woo, C. M.; Gholap, S. L. J. Am. Chem. Soc. 2011, 133, 7260-7263. (b) Woo, C. M.; Gholap, S. L.; Lu, L.; Kaneko, M.; Li, Z.; Ravikumar, P. C.; Herzon, S. B. J. Am. Chem. Soc. 2012, 134, 17262-17273.

(6) Birman, V. B.; Zhao, Z.; Guo, L. Org. Lett. 2007, 9, 1223-1225.

(7) Lee, H. G. Ph.D. Thesis, Harvard University, 2012.

(8) Compounds $\mathbf{9}$ and $\mathbf{1 0}$ exist as cyclic hydrates. $\mathbf{9}$ and $\mathbf{1 0}$ are the enantiomeric series to the natural product. $\pi$-system with the antibonding $\sigma^{*}$-orbital of the bridging $\mathrm{C}-\mathrm{O}$ bond (6, Scheme 1). ${ }^{9}$ An exocyclic enolate (C5-C4a) of $\mathbf{5}$, however, would have greater conformational flexibility and can thus achieve requisite orbital overlap for $\beta$-elimination. ${ }^{10}$ We exploited this stereoelectronic dichotomy of the oxanorbornanone system successfully in our initial reported studies ${ }^{4 \mathrm{a}}$ and achieved stereoselective oxidative enolate dimerization without $\beta$-elimination. Furthermore, we were able to subsequently fragment the oxygen bridge of 9 (Figure 2). However, displacement of the C4-phenylsulfone with various oxygen nucleophiles was low-yielding and the corresponding product could not be converted to the lomaiviticin core from the cyclic hydrate.

Unexpectedly, in our most recently published work, ${ }^{4 b}$ we were unable to fragment the oxygen bridge of the full aglycon carbon skeleton $\mathbf{1 0}$ (Figure 2). We attributed the unsuccessful fragmentation to the additional strain and rigidity that the $\mathrm{AB} / \mathrm{A}^{\prime} \mathrm{B}^{\prime}$-naphthalenes introduce to the system. Predicated on the two aforementioned observations, we embarked on a new route to synthesize a substrate with the correct C4-stereochemistry (Scheme 1, 5) and planned to introduce the naphthalene system after oxygen bridge fragmentation.

Scheme 2. Intramolecular Exo-Selective Furan Diels-Alder Reaction $^{a}$

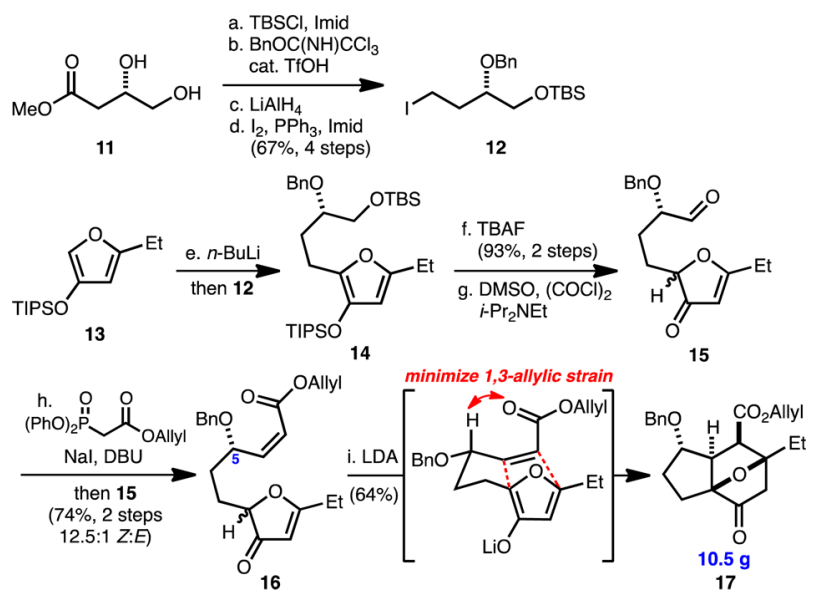

${ }^{a}$ Conditions: (a) TBSCl, Imid, $\mathrm{CH}_{2} \mathrm{Cl}_{2}, 0^{\circ} \mathrm{C}, 94 \%$; (b) $\mathrm{BnOC}(\mathrm{NH}) \mathrm{CCl}_{3}$, cat. $\mathrm{TfOH}, \mathrm{Et}_{2} \mathrm{O}, \mathrm{rt}, 81 \%$; (c) $\mathrm{LiAlH}_{4}, \mathrm{THF},-40{ }^{\circ} \mathrm{C}, 94 \%$; (d) $\mathrm{I}_{2}, \mathrm{PPh}_{3}$, Imid, $\mathrm{CH}_{2} \mathrm{Cl}_{2}$, rt, $88 \%$; (e) $n$-BuLi, THF, $-78 \rightarrow 0{ }^{\circ} \mathrm{C}$; $\mathbf{1 2},-78^{\circ} \mathrm{C}$; (f) TBAF, THF, $0{ }^{\circ} \mathrm{C} \rightarrow \mathrm{rt}, 93 \%$ (2 steps); (g) DMSO, $(\mathrm{COCl})_{2}, \mathrm{CH}_{2} \mathrm{Cl}_{2},-78{ }^{\circ} \mathrm{C}$; $i$-Pr $\mathrm{Pr}_{2} \mathrm{NEt},-78 \rightarrow-20^{\circ} \mathrm{C}$; (h) NaI, DBU, THF, $0^{\circ} \mathrm{C}$; then $15,-78^{\circ} \mathrm{C}, 74 \%$ (2 steps, 12.5:1 Z:E); (i) LDA, THF, $-78^{\circ} \mathrm{C}, 64 \%$.

The synthesis commenced with the selective TBSprotection of the primary hydroxyl of diol 11, which can be readily synthesized in two steps from $(S)$-malic acid (Scheme 2) ${ }^{11}$ Benzyl protection of the secondary hydroxyl

(9) (a) Tojo, S.; Isobe, M. Synthesis 2005, 1237-1244. (b) Jackson, S. R.; Johnson, M. G.; Mikami, M.; Shiokawa, S.; Carreira, E. M. Angew. Chem., Int. Ed. 2001, 40, 2694-2697. (c) Vogel, P.; Cossy, J.; Plumet, J.; Arjona, O. Tetrahedron 1999, 55, 13521-13642.

(10) (a) McMorris, T. C.; Staake, M. D.; Kelner, M. J. J. Org. Chem. 2004, 69, 619-623. (b) Jung, M. E.; Min, S. J. Tetrahedron 2007, 63, 3682-3701. (c) Krygowski, E. S. Ph.D. Thesis, Harvard University, 2008. See Supporting Information (Figure 1) for more details. 
Scheme 3. Stereoselective Oxidative Enolate Dimerization and Attempted Oxygen Bridge Fragmentation ${ }^{a}$

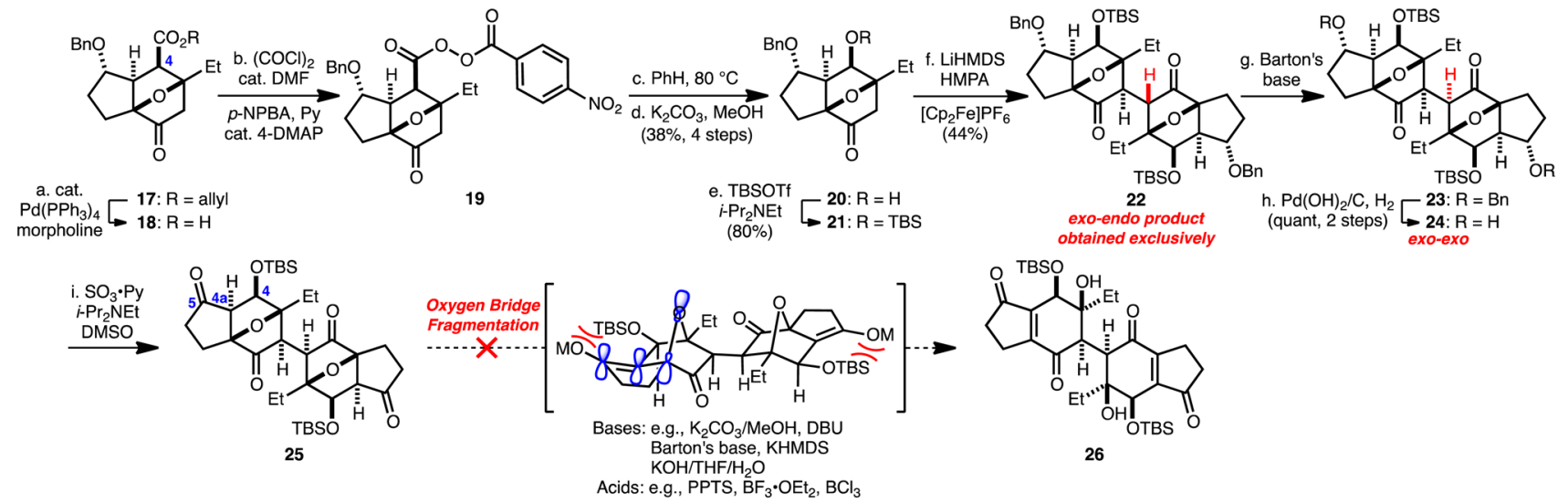

${ }^{a}$ Conditions: (a) $10 \mathrm{~mol} \% \mathrm{Pd}\left(\mathrm{PPh}_{3}\right)_{4}$, morpholine, THF, rt; (b) $(\mathrm{COCl})_{2}$, cat. DMF; $p$-NPBA, Py, cat. 4-DMAP, $\mathrm{CH}_{2} \mathrm{Cl}_{2}, 0{ }^{\circ} \mathrm{C} ;\left(\right.$ c) $\mathrm{PhH}, 80{ }^{\circ} \mathrm{C}$; (d) $\mathrm{K}_{2} \mathrm{CO}_{3}, \mathrm{MeOH}, 0{ }^{\circ} \mathrm{C}, 38 \%$ (4 steps); (e) TBSOTf, $i$ - $\mathrm{Pr}_{2} \mathrm{NEt}, \mathrm{CH}_{2} \mathrm{Cl}_{2}, 0^{\circ} \mathrm{C} \rightarrow \mathrm{rt}, 80 \%$; (f) LiHMDS, HMPA, THF, $-78^{\circ} \mathrm{C}$; then [Cp $\left.\mathrm{Cp}_{2} \mathrm{Fe}\right] \mathrm{PF} \mathrm{P}_{6},-78 \rightarrow$ $-55^{\circ} \mathrm{C}, 4 \mathrm{~d}, 44 \%$; (g) 2-tert-butyl-1,1,3,3-tetramethylguanidine (Barton's base), $\mathrm{MeCN},-5^{\circ} \mathrm{C}$; (h) $\mathrm{Pd}(\mathrm{OH})_{2} / \mathrm{C}, \mathrm{H}_{2}, \mathrm{THF}$, rt, quant (2 steps); (i) $\mathrm{SO}{ }_{3} \bullet \mathrm{Py}$, $i$ - $\mathrm{Pr}_{2} \mathrm{NEt}$, DMSO, $\mathrm{CH}_{2} \mathrm{Cl}_{2},-10{ }^{\circ} \mathrm{C}$.

group, reduction of the methyl ester, and formation of the corresponding iodide occurred smoothly to yield alkyl iodide 12. Lithiation of furan 13, followed by alkylation with 12, afforded coupled product 14, which upon global silyl deprotection with TBAF, provided the corresponding furanone alcohol (93\%, two steps). Swern oxidation then cleanly delivered aldehyde $\mathbf{1 5}$.

Aldehyde 15 was then converted to $(Z)$-enoate 16 (12.5:1 $Z / E)$, the Diels-Alder substrate, via a $Z$-selective modified Horner-Emmons reaction. ${ }^{12} \mathrm{We}$ anticipated that the stereoselectivity of the exo-selective ${ }^{13}$ intramolecular furan Diels-Alder reaction would be controlled by the single C5-stereocenter, which enforces a conformation where 1,3-allylic strain is minimized. Initial attempts to promote the Diels-Alder reaction by conventional thermal and Lewis acidic conditions failed to provide the desired cycloadduct in synthetically useful yields. We rationalized that tautomerization of the furanone to the requisite furan may be slow and that basic conditions may therefore promote the desired transformation. We discovered that treatment of 16 with $\mathrm{LDA}^{14}$ provided the Diels-Alder product 17 in $64 \%$ yield as a $10: 1$ mixture of separable diastereomers, favoring the expected cis-5,5 fusion product. This process presumably occurs via a stepwise MichaelMichael reaction sequence. We were able to prepare over $10 \mathrm{~g}$ of $\mathbf{1 7}$ using this protocol.

(11) (a) Gaunt, M. J.; Jessiman, A. S.; Orsini, P.; Tanner, H. R.; Hook, D. F.; Ley, S. V. Org. Lett. 2003, 5, 4819-4822. (b) Saito, S.; Ishikawa, T.; Kuroda, A.; Koga, K.; Moriwake, T. Tetrahedron 1992, 48, 4067-4086.

(12) Ando, K.; Oishi, T.; Hirama, M.; Ohno, H.; Ibuka, T. J. Org. Chem. 2000, 65, 4745-4749.

(13) The exo transition state, which results in cis-5,5 fusion product 17 , should be favored over the endo transition state, which would result in a highly strained trans-5,5 fusion product.

(14) Caine, D. S.; Paige, M. A. Synlett 1999, 9, 1391-1394.

(15) (a) Denney, D. B.; Sherman, N. J. Org. Chem. 1965, 30, 37603761. (b) Fujimori, K.; Shigeru, O. J. Chem. Soc., Perkin Trans. 2 1989, 1335-1348. (c) Meng, Z.; Danishefsky, S. J. Angew. Chem., Int. Ed. 2005, 44, 1511-1513.
With 17 in hand, an oxidative "carboxy-inversion" sequence for converting the C4-ester to a hydroxyl with retention of configuration was required (Scheme 3). ${ }^{15}$ First, the allyl ester of Diels-Alder product 17 was readily deprotected to carboxylic acid 18. Next, $p$-nitroperbenzoic acid ( $p$-NPBA) was coupled to carboxylic acid $\mathbf{1 8}$ via the acid chloride intermediate to afford crude diacyl peroxide 19, which underwent an ionic rearrangement ("carboxyinversion") upon heating to afford the corresponding acyl carbonate species. Methanolysis of this crude intermediate provided the desired secondary carbinol $\mathbf{2 0}$ as a single diastereomer (38\%, four steps). Protection of $\mathbf{2 0}$ as a TBS ether yielded the dimerization precursor, monomer 21. Utilizing the optimal oxidative enolate dimerization conditions developed in our group, ketone $\mathbf{2 1}$ was added to LiHMDS and HMPA in THF at $-78{ }^{\circ} \mathrm{C}$ to generate the corresponding lithium enolate, which was then exposed to $\left[\mathrm{Cp}_{2} \mathrm{Fe}\right] \mathrm{PF}_{6}$ and allowed to stir at $-55^{\circ} \mathrm{C}$ for 4 days. Contrary to our prior studies where only exo-exo dimerization was observed, ${ }^{4}$ exo-endo dimer 22 was obtained exclusively (44\%). It appears that although dimerization occurs with complete exo facial selectivity in the absence of any substitution on the oxanorbornanone carbon framework, the C4-substituent (pseudoaxial sulfone) plays a crucial role in reinforcing the exo-exo selectivity in our prior more complex polycyclic systems. ${ }^{4}$ Fortunately, 22 could be selectively equilibrated to the exo-exo dimer $\mathbf{2 3}$ by treatment with Barton's base.

With exo-exo dimer $\mathbf{2 3}$ in hand, the benzyl ethers were cleaved and the corresponding diol was oxidized to afford 1,4-diketone dimer 25. Fortuitously, 25 did not exist as a cyclic hydrate if silica gel column chromatography was avoided, which is in contrast to our previous systems ${ }^{4}$ (Figure 2) where the analogous C5-ketone substrates existed exclusively as the cyclic hydrates. This suggests that the C4-stereochemistry has subtle yet far-reaching stereoelectronic consequences on the system. Unfortunately, all 
attempts to fragment the oxygen bridge were unsuccessful. In all cases, either nonspecific decomposition or no reaction was observed. ${ }^{16}$ Surprisingly, deuterium incorporation studies (KOD in THF) revealed 100\% deuterium incorporation at $\mathrm{C} 4 \mathrm{a}$ of $\mathbf{2 5}$. Unlike the original successful model studies where the dimer contained a pseudoaxial C4-phenylsulfone (Figure 2, 9), we rationalized that fragmentation is disfavored due to a 1,3-allylic interaction between the enolate (C5-C4a) oxygen of 25 and the pseudoequatorial C4-TBS-ether that must occur during the transition state in order to achieve proper orbital overlap for fragmentation to occur. Unfortunately, moving to a sterically smaller protecting group (MOM) and even the free hydroxyl did not remedy this problem.

In line with our hypothesis, we rationalized that the C4-epimer of $\mathbf{2 5}$ would not suffer from an unfavorable 1,3-allylic-type interaction during oxygen bridge fragmentation. To this end, 18 was subjected to a one-pot Barton radical decarboxylation-oxidation reaction (Scheme 4). First, the Barton ester was formed from carboxylic acid 18 by using $S$-(1-oxido-2-pyridinyl) 1,1,3,3-tetramethylthiouronium hexafluorophosphate (HOTT). ${ }^{17}$ Upon complete formation of the Barton ester, the reaction was saturated with $\mathrm{O}_{2}$ and $\mathrm{Sb}(\mathrm{SPh})_{3}$ was added. ${ }^{18}$ This protocol afforded alcohol 27 as a 2:1 mixture of diastereomers, favoring the desired epimer in $46 \%$ isolated yield. ${ }^{19}$ Protection of 27 as a TBS ether then yielded the dimerization precursor, monomer 28.

Oxanorbornanone $\mathbf{2 8}$ underwent successful oxidative enolate dimerization to exclusively provide exo-exo dimer 29. Benzyl ether cleavage and subsequent oxidation afforded cyclic hydrate 31, which gratifyingly underwent successful fragmentation upon treatment with $\mathrm{KOH}$ at $0{ }^{\circ} \mathrm{C}$, confirming our suspicion that the $\mathrm{C} 4$-stereocenter has far-reaching stereoelectronic effects. Bisenone product 32 was then converted to C4-epi-lomaiviticin B core 34 in two steps, involving (1) dehydration of cyclic hydrate 32 in the presence of $\mathrm{MgSO}_{4}$ to yield C4-epi-lomaiviticin A core 33 and (2) stirring 33 with catalytic $p$-TsOH to provide C4-epi-lomaiviticin B core 34 (62\%, three steps).

In summary, we have reported a synthesis of the C4-epilomaiviticin A and B cores, the first time this has been achieved in our lab. Noteworthy transformations include

(16) Even the cyclic hydrate form of $\mathbf{2 5}$, which can be readily accessed by exposure to $\mathrm{KOH}$ in $\mathrm{H}_{2} \mathrm{O} / \mathrm{THF}$, did not undergo the desired fragmentation.

(17) Garner, P.; Anderson, J. T.; Dey, S. J. Org. Chem. 1998, 63, $5732-5733$.

(18) (a) Barton, D. H. R.; Bridon, D.; Zard, S. Z. Tetrahedron 1989, 45, 2615-2626. (b) Zhu, J.; Klunder, A. J. H.; Zwanenburg, B. Tetrahedron 1995, 51, 5099-5116.

(19) Use of the more conventional Barton radical decarboxylationoxidation conditions (Barton ester formation, followed by exposure to $\mathrm{O}_{2}, t$-BuSH, and a sunlamp, then reduction with $\mathrm{PPh}_{3}$ ) afforded the alcohol product in a higher 4:1 dr, but in a somewhat lower isolated yield of the desired diastereomer $(37-40 \%)$.
Scheme 4. Successful Oxygen Bridge Fragmentation and Conversion to C4-Epi-Lomaiviticin A (33) and B (34) Cores ${ }^{a}$
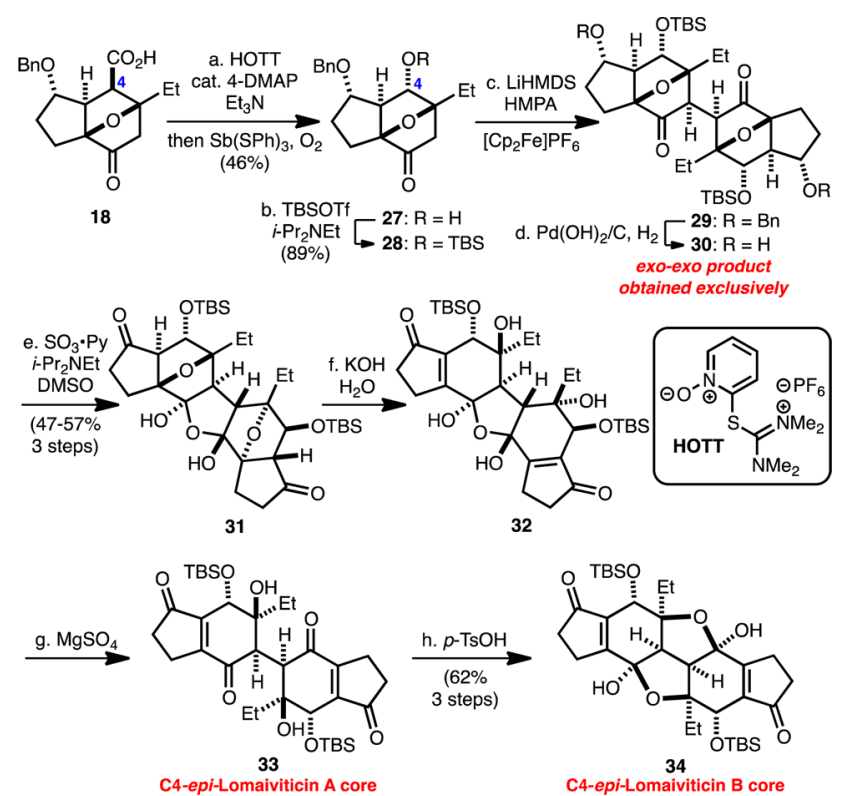

${ }^{a}$ Conditions: (a) HOTT, cat. 4-DMAP, $\mathrm{Et}_{3} \mathrm{~N}, \mathrm{THF}$; then $\mathrm{Sb}(\mathrm{SPh})_{3}$, $\mathrm{O}_{2}, \mathrm{rt}, 46 \%$; (b) TBSOTf, $i-\mathrm{Pr}_{2} \mathrm{NEt}, \mathrm{CH}_{2} \mathrm{Cl}_{2}, 0{ }^{\circ} \mathrm{C} \rightarrow \mathrm{rt}, 89 \%$; (c) LiHMDS, HMPA, THF, $-78{ }^{\circ} \mathrm{C}$; then $\left[\mathrm{Cp}_{2} \mathrm{Fe}_{\mathrm{PF}},-78 \rightarrow-60{ }^{\circ} \mathrm{C}\right.$, $5 \mathrm{~d}$; (d) $\mathrm{Pd}(\mathrm{OH})_{2} / \mathrm{C}, \mathrm{H}_{2}$, THF, rt; (e) $\mathrm{SO}_{3} \bullet \mathrm{Py}, i$-Pr $2 \mathrm{NEt}$, DMSO, $\mathrm{CH}_{2} \mathrm{Cl}_{2}$, $0{ }^{\circ} \mathrm{C} \rightarrow \mathrm{rt}, 47-57 \%$ (3 steps); (f) $\mathrm{KOH}, 3: 1 \mathrm{THF} / \mathrm{H}_{2} \mathrm{O}, 0{ }^{\circ} \mathrm{C}$; (g) $\mathrm{MgSO}_{4}$, $\mathrm{PhH}, 80{ }^{\circ} \mathrm{C}$; (b) $p$-TsOH, $\mathrm{PhH}, \mathrm{rt}, 62 \%$ (3 steps).

an intramolecular exo-selective furan Diels-Alder reaction to construct the oxanorbornanone system, a stereoselective oxidative enolate dimerization to establish the key $\mathrm{C} 2-\mathrm{C} 2$ ' bond, and successful oxygen bridge fragmentation to generate the lomaiviticin core. Crucial to the success of our oxygen bridge fragmentation was the discovery of a subtle stereoelectronic effect imparted by the C4-stereocenter, which necessitated the synthesis of a substrate with the opposite C4-stereochemistry to that found in the natural product. Current efforts are now focused on the elaboration of the lomaiviticin B core 34 to the full carbon skeleton of the aglycon and will be reported in due course.

Acknowledgment. A.S.L. acknowledges an NDSEG and an NSF predoctoral fellowship for financial support. A.S.L. thanks Brian B. Liau (Harvard University) for helpful discussions.

Supporting Information Available. Experimental procedures, spectroscopic data, and copies of ${ }^{1} \mathrm{H}$ and ${ }^{13} \mathrm{C}$ NMR. This material is available free of charge via the Internet at http://pubs.acs.org.

The authors declare no competing financial interest. 